\title{
Relations between Natural Phenomena and Solar Activity in the Oceanographic and Forest Fields
}

\author{
Silvana Fais ${ }^{1}$, Michele Puxeddu ${ }^{2}$ \\ ${ }^{I}$ Dipartimento di Ingegneria Civile, Ambientale e Architettura (DICAAR) - Università di Cagliari - Italy \\ ${ }^{2}$ Dottore in Scienze Forestali - Via Darwin 11 - 09126 Cagliari - Italy, Tel. +39-070-373361
}

\begin{abstract}
A great number of studies on the relationship between solar activity and various terrestrial phenomena, both in the climatic and geophysical fields, have been carried out over several decades. In the present work we analyse the shorter oscillations of the solar activity such as the ones recognized in the climatic and oceanographic oscillations, for which, as it is known, longer series of observations are unavailable. Specially we analyse both the sunspot series (Wolf relative number series) considered an index of solar activity and observed since 1700 and the series of the mean sea level variation of the longest ones available in the word and relative to three oceanographic stations in Poland (Swinoujscie), France (Brest) and Italy (Venezia), whose geographical distribution made the comparison interesting. Because of the sea level evolution fluctuate in intensity, an analysis of these fluctuations and their possible correlation with the solar activity was considered of great interest to give a contribution for the explanation of the various interactions between natural phenomena and other problems relating to the forecasting of the climatic evolution.
\end{abstract}

Keywords: Solar activity, sunspot series, spectral analyses.

\section{Introduction}

The relationship between solar activity and various terrestrial phenomena, both in the climatic and geophysical fields, have been studied over several decades. The dendrology, the cyclic behaviour in the stratification of the glaciers are also related to solar activity. From the analysis of these phenomena, a great deal of interesting information on the effect of the solar activity can be deduced, although the mechanisms are not easily explainable. Some papers [1,2] discussed on the evolution in time of natural fluctuating phenomena which represent many topics in different sectors of Sciences, like climatic events, terrestrial magnetic field, sun radiation, sea level, growth of trees, etc.. Fais \& Mosetti [3] focused their attention on the study of the solar activity trend, analysing the Wolf number sunspot series.

Many investigators recognized the 11-years period in many fluctuating terrestrial phenomena. The same period was formerly recognized in the solar activity. Despite the 11-years period, although dominant, is not the only periodicity recognized in the Wolf number series.

In this paper, we focused our attention on the analysis of the relationship between sunspot and mean sea level temporal evolution series. The study was performed analysing three different marigraphic stations (Tab.1) chose geographical distribution made the comparison interesting for our target and chosen among the ones having the longest series of data.

Table 1 - Analysed marigraphic stations

\begin{tabular}{|c|c|c|}
\hline Marigraphic station & Country & Atlantic Ocean and adjacent seas \\
\hline Venezia & Italy & Adriatic \\
\hline Brest & France & Atlantic \\
\hline Swinoujscie & Poland & Baltic \\
\hline
\end{tabular}

The verification of the coincidence (or similarities) of the periodical components of the temporal evolution of the sea level on stations distributed on different seas, is not accidental.

\section{Data Analysis}

The study was performed both for the sea level and sunspot series by the spectral analysis carried out by the Fast Fourier Transform (FFT) [4,5] and Maximum Entropy Method (MEM) [6] that has a higher resolution on short series analysis than FFT. The sunspot series analysis was also integrated by filtering techniques.

The comparison between the sea level series of Brest and Swinoujscie that are longer with respect Venice, was done both by FFT and MEM methods, while the sea level series of Venice was analysed only by MEM method due to its shortness (93 years). To improve the analysis it was extracted from each series, a partial 
series relative to the interval 1872-1964, common to the three stations. Therefore the sea level series of 93 years were analysed by MEM technique. The frequency step was $1 / 93$ cycles/year and the frequency range was from 0 to 0.5 cycles/year. The most significant peaks appearing in the spectra have been summarized in Table 2 .

Table 2 - Spectral peaks (MEM application) showing the periods present in the 1872-1964 time interval in the series of Brest, Swinoujscie and Venice. Values are in years.

\begin{tabular}{|c|c|c|}
\hline Brest & Swinoujscie & Venezia \\
\hline 37.2 & 44.0 & 31.0 \\
\hline 20.6 & 23.5 & 20.6 \\
\hline 12.4 & 15.5 & 11.6 \\
9.3 & 10.9 & 9.3 \\
\hline & 8.8 & 7.4 \\
\hline 6.9 & 7.7 & 6.2 \\
5.6 & 6.4 & 5.2 \\
\hline 4.6 & 5.5 & 4.7 \\
4.1 & 4.7 & 4.4 \\
3.9 & 4.4 & 4.0 \\
\hline & 3.9 & 3.6 \\
\hline 3.4 & 3.5 & 3.0 \\
\hline
\end{tabular}

The analysis of the frequency content of the sunspot series was focused on the shorter oscillations such as the ones found in the sea level, for which longer observation series are not available. Anyway it is to point out that the sunspot series observed since the 1700 , is not enough long for analysing long periodicities with the necessary precision. In this paper, the spectral composition of the sunspot series was performed by the FFT technique using the "Decimation in time algorithm" [7] also integrating the analysis by filtering techniques. In fact, the components of short period were filtered and some biases removed. The filtered spectrum shows remarkable peaks at the periods of 4.3, 4.7, 5.6, 8.0, 11.3, 16.0, 22.6 and 51.2 years.

\section{Results}

The periodic components found in the sea level long period oscillations of the examined stations are coincident or very similar and therefore characteristic. In fact, as recognized in earlier papers, cyclic components of the sea level variation can be considered "true" if the same components, even if with different amplitude and phase, occur in different localities. The spectral composition of the sunspot series identifies spectral peaks that are close to the ones found in the mean sea level evolution of the considered stations. Some discrepancy is probably due to the spectral analysis applied to short series of data and for this reason unable to extract precise periods of the components. Moreover, interference by adjacent peaks can be also occurred. The same periodicities are also similar to known climatic cycles and more in general are in agreement with those characterizing others oscillating natural phenomena [1,2]. Consequently, it can be deduced that there is a connection between solar activity and many terrestrial fluctuating phenomena although the mechanisms are not easily explainable. The study of the periodicities present in the sunspot series considered an index of solar activity and their influence in the oceanographic and climatic phenomena is of great importance to understand the complex mechanisms relating to the forecasting of climatic evolution.

\section{References}

[1]. F. Mosetti. - On temporary fluctuations of some natural phenomena, Boll. Geof. Teor. Appl., VIII (29), 1966, 62-76.

[2]. F. Mosetti - Natural and geophysical fluctuations. The meaning and their detection, O.G.S. Silver Ann., Oss. Geof. Sper. Ed., Trieste, 1984, 11-15.

[3]. S. Fais, F. Mosetti - On periodicities in the sunspot series, Boll. Geof. Teor. Appl., XXXI (123-124), 1989, 315-320.

[4]. J.W. Cooley, J.W. Tukey- An algorithm for the machine calculation of complex Fourier series, Math. Computation, 19, 1965, 297301.

[5]. S.L. Marple - Digital spectral analysis with applications (Prentice-Hall, 1987).

[6]. I. Barrodale, R.E. Erickson - Algorithms for least-squares linear prediction and maximum entropy spectral analysis, Geophysics, 45(3), 1980, 420-432.

[7]. A.V. Oppenheim, R.V. Schafer-Digital signal processing (Prentice-Hall, New Jersey, 1975). 